\title{
A REVOLUÇÃO RUSSA E O BRASIL
}

\section{André Moysés Gaio* \\ Daniel Jorge Salles de Freitas**}

RESUMO

O artigo buscará apresentar o impacto da Revolução Russa no Brasil; para tal fim faremos uma breve retrospectiva da história dos movimentos populares e suas repercussões públicas, seja na intelectualidade brasileira, seja nas instituições estatais e na imprensa. Outro objetivo será apresentar a criação do Partido comunista do Brasil (PC do B), bem como uma interpretação do seu possível fracasso político. O material pesquisado é de cunho bibliográfico, principalmente os principais trabalhos escritos sobre a trajetória dos movimentos sociais e do PC do B. A conclusão é de que não há, realmente, uma explicação convincente sobre da presença subalterna do partido na vida política brasileira.

Palavras-chave: Revolução Russa. Movimentos sociais. Partido Comunista do Brasil

\section{THE RUSSIAN REVOLUTION AND BRAZIL}

\section{ABSTRACT}

This article seeks to discuss the impact of the Russian Revolution in Brazil. To that end, a brief retrospect of the history of popular movements and their public repercussions is first performed regarding the Brazilian intelligentsia, government institutions and in the press. Another goal is to present the creation of the Brazilian Communist Party (Partido Comunista do Brasil, PC do B), as well as in interpretation of its arguable political failure. The material surveyed comes from bibliographic works written about the history of social movements and the PC do B. The conclusion is that there is not indeed a really convincing explanation about the subordinate presence of said party in the Brazilian political life

Keywords: Russian revolution. Social movements. Communist Party of Brazil

* Doutor em História Social, Professor do Departamento de Ciências Sociais da Universidade Federal de Juiz de Fora. Autor de 4 livros. Contato: amgbr68@yahoo.com.br.

** Doutor em Ciências Sociais pela Universidade Federal de Juiz de Fora. Contato: danieljs.freitas@hotmail.com. 


\section{INTRODUÇÃO}

A passagem dos 100 anos da Revolução Russa tem estimulado reflexões, conferências e debates sobre a importância desse evento no Brasil. Quem se dedicar ao estudo da questão precisará recorrer à sua própria biblioteca ou qualquer uma que esteja ainda equipada para disponibilizar obras dos anos de 1960, de 1970 e 1980, no máximo. O mesmo ocorrerá para quem desejar escrever algo sobre o marxismo no Brasil ou sobre o pensamento marxiano em geral.

A edição sobre a literatura marxiana $e$ marxista há muito não são objeto de desejo seja de editoras, seja de escritores. Tal situação decorre de diagnósticos variados: a derrota da teoria marxiana frente ao neoliberalismo, o abandono, simplesmente, da utilização do mesmo para se utilizar de outras perspectivas da moda acadêmica, a falácia da crise das grandes narrativas etc. O livro "O Fim da Utopia" de Jacoby (1999) explica grande parte dos problemas enfrentados para lidar com tal questão, pois aponta todos os principais elementos para as derrotas das esquerdas e as dificuldades para contar com suas histórias pretéritas.

Quando nos voltamos para uma reconstrução histórica sobre a repercussão da Revolução Russa no Brasil, é preciso, então, recuperar o que foi escrito numa época que ainda a história que aqui se praticava, pois ainda não se praticava o que é chamado de história cultural ou história dos aspectos secundários de algo.

O certo é que escrever sobre as repercussões a revolução russa no Brasil é enfrentar os desafios supracitados; no entanto, o material existente permite refazer a alguns caminhos e desafios que nos permitem enfrentar o tema com alguma segurança.

\section{UM POUCO DA HISTÓRIA DA MOBILIZAÇÃO POPULAR}

A literatura sobre os quilombos, as revoltas que ocorreram no segundo reinado, a revolta da chibata, as greves de 1917 e 1918, comprovaram que as lutas sociais estiveram presentes em nossa história; contudo, em nossas rupturas institucionais, seja a independência (excetuando o episódio baiano) e a República (pela derrota da ala de Silva Jardim) não representaram episódios em que a questão social e a questão do trabalho estivessem no centro das motivações dos setores que as promoveram. Nem mesmo a questão democrática era central.

Iniciativas de criação de jornais operários foram catalogadas de forma competente por Tavares (1983) a partir do século XIX. Desde 1837, vários deles com denominações variadas como o socialista, o proletário, a revolução, o trabalho, alguns se referindo a datas como $1^{\circ}$ de maio ou representando profissões variadas. Vários são escritos em outras línguas, principalmente a espanhola. $\mathrm{O}$ autor citado não analisou com profundidade sobre o conteúdo das matérias dos referidos jornais, mas fez alusão a alguns que se assumiam como socialistas, embora sem revelar se a maioria dos mesmos incorporava a doutrina de algum autor específico; entretanto, vagas citações de Fourier (1772-1837), Saint-Simon (1760-1825), Blanqui (1808-1881) e Proudhon (1809-1865) foram mencionadas pelo mesmo (TAVARES, 1983, p. 79). Tavares conseguiu, através de uma pesquisa exaustiva, encontrar 123 jornais publicados entre 1837 e 1899 . Quantas pessoas estavam reunidas em torno desses jornais e quais os impactos políticos dos mesmos não foram revelados. Parece-nos, na verdade, que eram núcleos de pouca duração e formado por poucas pessoas.

Dois congressos socialistas ocorreram no início da República e dois partidos socialistas foram criados no mesmo período, partidos esses de curta duração segundo Dulles (1977, p. 22). A primeira década do século XX, precisamente entre os anos de 1901 a 1908, foi marcada por muitas greves, quase sempre para defender o pagamento de salários, aumento dos mesmos e limitação da jornada de trabalho. Os movimentos eram duramente reprimidos. O decreto 1641 regularizou a expulsão de estrangeiros do país, visto que, existiam italianos e espanhóis, principalmente, nas lideranças de movimentos grevistas e de organização operárias.

Fundada em 1908 e reorganizada em 1913, a Confederação Operária Brasileira foi importante instrumento para aprimorar a organização das lutas dos trabalhadores, especialmente a nova onda de greves ocorridas entre 1911 a 1914. Tais movimentos, contudo, eram muito concentrados 
no Rio de Janeiro e em São Paulo e, além disso, os movimentos eram muito divididos, especialmente nas lideranças, marca sensível dos movimentos socialistas e anarquistas.

As greves de 1917 em São Paulo e no Rio de Janeiro paralisaram um grande número de empresas, embora as reivindicações estivessem aquém do que foi reivindicado nos anos anteriores: aumento de salários, regulamentação da jornada de trabalho das mulheres e dos menores, diminuição dos preços de produtos de primeira necessidade. Repressão e descumprimento dos acordos foram a tônica segundo Dulles (1977, p. $56)$.

\section{SOCIALISTAS E ANARQUISTAS}

As correntes políticas acima estão no plural porque era difícil extrair uma matriz programática única de ambas. $\mathrm{Na}$ coletânea feita por Moraes Filho (1981) cujo título é "O Socialismo Brasileiro", encontramos manifestos, programas de partidos, opiniões e propostas socialistas brasileiros. $\mathrm{O}$ que podemos afirmar é que nenhum caminho para o socialismo foi elaborado. A tônica, num resumo que pode não ser o mais justo, é a ênfase no esclarecimento de quais seriam as bases civilizacionais que o país teria que conquistar: propostas para a educação de base e criação de universidades, remodelação intelectual, moral, jurídica, política, melhoria das condições de trabalho e de saúde (MORAIS FILHO, 1981, p. 27).

A pesquisa de Magnani (1982) procurou revelar as teses dos vários grupos anarquistas, principalmente de suas bases em São Paulo. A autora encontrou através das publicações da época, duas tendências dentro do que a mesma denominou anarquismo libertário: o anarcocomunismo e o anarco-sindicalismo, sendo a última a corrente predominante.

Segundo a autora

as duas tendências fundamentais partem dos mesmos princípios básicos e têm o mesmo objetivo final(a derrubada do capitalismo), divergindo na interpretação da ação da ação direta, o que envolve a questão fundamental da organização dos oprimidos; divergindo também quanto à forma de organização da sociedade anárquico-sindical de produtores e comunas de livre associação (MAGNANI, 1982, p.58).

Os anarquistas, tanto quanto os socialistas e comunistas tinham pouco preparo intelectual, seja pela precária educação formal, mas, principalmente, porque a literatura que deveria inspirar os militantes não era acessível em língua portuguesa e também pelo desconhecimento de língua estrangeira. Os primeiros rejeitavam qualquer ideia de partido político, preferiam a ação direta ou exclusivamente através dos sindicatos. Eram fundamentalmente anticapitalistas, anticlericais, contra o Estado e contra o nacionalismo. Adeptos da revolução contra o capitalismo, embora não tematizassem com alguma profundidade o que iria vir após a ação revolucionária.

Profundamente divididos (o que nos parece ser característico das organizações de esquerda), por questões muitas vezes secundárias, a ação anarquista padeceu de muitas deficiências e foi objeto de uma dura repressão, todavia os anarquistas tiveram grande importância na greve de 1907 em São Paulo.

De acordo com Magnani (1982, p. 151), os anarquistas não produziram importantes análises sobre o Brasil, concentrando em suas preocupações sobre os Estados de São Paulo e Rio de Janeiro. A autora avança afirmando que não apoiavam a industrialização e eram totalmente neutros em relação ao capital estrangeiro. Contrários à participação política, apenas restaria a ação direta e/ou através dos sindicatos.

Precisamos sublinhar que a avaliação do movimento anarquista realizada, especialmente por autores vinculados à trajetória do Partido comunista do Brasil (posteriormente partido Comunista Brasileiro), foi percebida de forma negativa por motivos vários. Konder (1988), por exemplo, embora teça aos anarquistas alguns elogios, afirma, no entanto, que o desconhecimento da obra de Karl Marx pelos mesmos, foi um pecado mortal, despreparandoos para realizar qualquer diagnóstico sério sobre a realidade brasileira.

Seria com esse legado que a criação do futuro Partido Comunista (PC do B) iria se defrontar. Os fundadores do mesmo eram anarquistas que 
se defrontaram com a Revolução Russa e que os forçaria a tomar novas posições, frequentemente influenciadas por suas formações políticas pretéritas.

\section{O SOCIALISMO, MARX, NA IMPRENSA E NA INTELECTUALIDADE}

O tema das lutas operárias apareceu na imprensa brasileira e no Congresso Nacional a partir da comuna de Paris em 1871. O debate no Congresso girou em torno da questão da vida de comunards ao Brasil e a repulsa foi generalizada e aprovaram uma moção de aplauso aos vitoriosos por "defenderem a causa da civilização" e os "princípios do cristianismo"

No livro "Marx, o socialismo e o Brasil" (Tavares, 1983, p. 147-152) figura como anexo um texto de Raimundo Magalhães Júnior, escritor já falecido (1907-1981) e então membro da Academia Brasileira de Letras, escreveu sobre o tratamento que a imprensa do Império dava a Marx. No texto Magalhães observou que o escritor alemão era "tratado de maneira respeitosa" e considerado "apenas como um filósofo pacato e inócuo", uma pessoa inofensiva e um utópico. Cita também Magalhães Júnior um artigo do jornal "A Reforma" (órgão do Partido Liberal), em que era desmentida a participação de Marx na Comuna de Paris. O autor também citaria um necrológio de Marx pelo jornal Gazeta de Notícias em 16 de abril de 1883, em que Marx foi retratado com como um grande intelectual e "ilustre finado" e que mereceria uma biografia.

No livro em que estuda a recepção de Marx e da literatura marxista Leandro Konder (op.cit), com certeza na melhor contribuição já escrita sobre o tema, concorda com Bandeira e Melo (1967) ter havido no Brasil um desconhecimento quase em toda intelectualidade e nas lideranças operárias das obras de Marx de autores marxistas. $\mathrm{O}$ autor entra em polêmicas desnecessárias para saber se um autor que citou Marx realmente leu a obra do pensador alemão e cita os nomes de Lima Barreto (1881-1922) e Euclides da Cunha (18661909) como autores que além de conhecerem alguma obra de Marx tinham simpatia pela causa operária.

Konder também escreveu que a recepção de Marx se misturava com a "fé cientificista" e a "tradição cristã", enfim ele sintetiza que a "abertura espiritual e frouxidão conceitual caminhavam, infelizmente juntas" (KONDER, 1999, p. 84).

\section{A REVOLUÇÃO RUSSA E O BRASIL}

Segundo Bandeira e Melo (1967) havia um desconhecimento quase total sobre a Revolução Russa no Brasil, da imprensa aos intelectuais e militantes políticos. Aos poucos a repercussão da mesma foi impondo-se como tema e exigindo reflexões dos movimentos populares sobre novas formas de organização política e de teorias que pudessem representar o novo momento trazido pela revolução socialista. $O$ escritor Lima Barreto foi um dos poucos escritores a tematizar diretamente o tema da revolução socialista em artigo publicado no ano de 1919 cujo título era "Sobre o maximalismo" e, posteriormente incorporado ao livro "Bagatelas" (1956). Inicia o artigo escrevendo contra "os doutores da burguesia que se limitam a acoimar Lênin, Trotsky e seus companheiros vendidos aos alemães" e em outro trecho faz clara alusão à Revolução Russa:

No meu artigo "no ajuste de contas" inspirado nas vagas coisas sobre a Revolução Russa, de que tinha notícia, eu pedia que se pusesse em prática quatro medidas principais: a) supressão da dívida interna [...] b) confiscação dos bens das ordens religiosas [...] c) Extinção do direito de testar; as fortunas por morte de seus detentores, voltavam para a comunhão [...] d) Estabelecimento do divórcio completo (BARRETO, 1956, p. 162).

A literatura sobre o tema demonstra ter havido uma multiplicação de partidos, greves e insurreições após 1917. Os primeiros de maio de 1918 e 1919 foram momentos de agitação e reinvindicações trabalhistas comandadas pela Liga comunista feminina ${ }^{1}$, por novo partido socialista (1917), um partido comunista fundado em 1919. As mobilizações também se espalhavam: São Paulo, Pernambuco, Rio Grande do Sul, Rio de Janeiro, Minas Gerais, entre outros Estados.

Seguiu-se a criação de vários comitês de

1 A Liga é mencionada em muitos trabalhos, porém não há informações sobre sua data de criação e formas de atuação. 
inspiração política diversa para arrecadar recursos visando a sobrevivência da Rússia socialista. Dentre as correntes destacaram-se todos os tipos de anarquistas e socialistas; porém, ao mesmo tempo, os vários grupos anarquistas no decorrer de 1920/1921 iniciaram duras críticas ao regime socialista, especialmente quanto ao fechamento dos sovietes, à censura à imprensa, à domesticação dos sindicatos eà repressão à revolta anarquista de Kronstadt (março de 1921) liderada por Trotsky (1879-1940). O ambiente político no interior das lideranças dos movimentos populares tornouse extremamente difícil levando-se em conta o enorme número de divergências entre as mesmas. Konder (1999, p. 127), relacionando o fim do anarco-comunismo no Brasil aponta que em vários lugares do país grupos comunistas começam a estudar alguns textos de Lênin e em 1921, segundo o mesmo autor, teriam se acelerado as articulações para a fundação do Partido Comunista do Brasil, completamente desvinculado da então Internacional Comunista. Um nome em destaque nesse movimento foi Astrogildo Pereira (1890-1965), admirador de Machado de Assis e egresso do movimento anarquista, tinha talento organizativo e ampla aceitação nas então lideranças do movimento operário, inclusive tendo criado, em 1921, a revista chamada "Movimento Comunista".

A fundação do Partido Comunista do Brasil resultou de um congresso realizado entre 25 e 27 de setembro de 1922. Foram nove delegados ao todo, dentre eles interessante citar as profissões: dois funcionários púbicos, eletricista, operário gráfico, dois alfaiates, artesão, vassoureiro. Há pouca informação sobre a fundação do $\mathrm{PC}$ do B; sabemos que todos eram de extração anarquista, sejam anarco-sindicalistas ou anarcocomunistas. Konder aponta duas situações que podem explicar as poucas informações sobre os integrantes da primeira direção eleita: a primeira era de que os próprios fundadores não tinham a dimensão histórica da criação de um partido comunista e por isso não preservaram um grande estoque de informações. A segunda, de acordo com o mesmo autor, foi o confisco, em junho de 1923, de todos os arquivos do PC do B (1999, p. 130-131). Dois grandes problemas são sublinhados pela literatura que se debruçou sobre a construção do $\mathrm{PC}$ do B. O primeiro se relaciona à quase total ausência de literatura marxiana e marxista à disposição daqueles que se empenharam na constituição de um partido comunista. O que existia, mesmo assim em número precário, era literatura escrita em francês, mas de acesso restrito. Vale aqui o esclarecimento de Carone:

O crescimento do PCB, na década de 1920, não é acompanhado por um processo paralelo editorial. Por falta de recursos, por incapacidade de tomar iniciativas mais complexas financeiramente, por passar por momentos de incertezas, o partido elabora um número muito pequeno de publicações durante os anos de 1922 a 1930. (...). Nesta fase do processo histórico, o PCB procura se consolidar organizativamente, sem aprofundar mais a questão ideológica (CARONE, 1986, p. 63).

Informação corroborada por Tavares (1983), que após um estudo criterioso chegou à conclusão que, sejam marxianos, sejam marxistas, antes da década de 1930 foram publicados dois títulos e na década de 1930, três (TAVARES, 1983, p. 118). É interessante observar que no excelente trabalho de Tavares o "O Capital", por exemplo, aparece em 1878 a partir de um resumo de Carlo Cafiero e a publicação mesmo da edição integral ocorreu em 1945.

O segundo problema é a pouca atenção, segundo Aricó (1982), que Marx e Engels deram à América Latina. Vale a citação do autor:

É indiscutível que a pouca atenção que Marx e Engels deram à América Latina, definida por alguns autores como uma soberana indiferença, deve ter influenciado "muitíssimo o destino teórico do continente no seio da tradição socialista" e que seu "inepto panfleto contra Bolívar ou seu elogio apressado da invasão do México pelos ianques" não podiam ajudar muito seus discípulos na tarefa de se localizar adequadamente no terreno do reconhecimento nacional latino-americano (ARICÓ, 1982, p. 33).

É notório o etnocentrismo no pensamento de Marx e sua pouca atenção dada à questão nacional, embora no final da vida se interessasse 
vivamente pela Rússia, estabelecendo um amplo debate com um grupo de intelectuais e militantes autodenominados Populistas Russos.

Os pecados originais do Partido Comunista do Brasil

$\mathrm{Na}$ modesta literatura sobre o Partido Comunista do Brasil - Dulles (1977, 1985), Carone (1982a, 1982b), Chilcote (1982), Vinhas (1982), Zaidan Filho (1985), Konder (1988), Pandolfi (1995), Segatto (1995) e Brandão (1997) - poucos são os livros que enfrentam firmemente o desafio de explicar tanto o isolamento do partido, sua precária presença na vida cultural brasileira e seu definhamento progressivo. Uma explicação singular, embora não acreditemos que seu conteúdo seja convincente, mas que é digno de nota, é a de Konder (1988), em sua exposição sobre o modo de pensar dialético revelado já no primeiro capítulo do livro. Em um parágrafo ele resume o que seria a concepção verdadeira do pensar dialético:

$\mathrm{O}$ modo de pensar dialético - atento à infinitude do real e à irredutibilidade do real ao saber - implica um esforço constante da consciência no sentido de ela se abrir para o reconhecimento do novo, do inédito, das contradições que irrompem no campo visual do sujeito e lhe revelam a existência de problemas que ele não estava enxergando. A exigência do reconhecimento de todas as contradições pode entrar em choque (e, de fato, com frequência entra) com exigências de outro tipo, que são exigências ligadas às tarefas práticas urgentes que a luta política apresenta aos revolucionários. (KONDER, 1988, p.09).

Segundo o autor essa concepção afastaria a dialética do legado de Hegel, de Engels, e de Bukhárin.

Esforçou-se também o autor em demonstrar o papel essencial da práxis na interpretação que Marx fez da dialética:

A dialética fundada sobre a práxis se tornou, com Marx, muito mais suscitadora de problemas do que uma eficiente fornecedora de respostas às perguntas que os marxistas tinham de se fazer, no plano filosófico (KONDER, 1988, p. 12).
Enfim, a dialética, segundo Konder, seria o único modo de pensar capaz de trabalhar com conceitos fluidos para dar conta da instabilidade do real, de sua vertiginosa transformação contínua e de suas inumeráveis contradições (1988, p. 14-15).

Em seguida a argumentação de Konder se dedicaria a demonstrar a incapacidade dos comunistas brasileiros para pensarem de forma dialética: pelo desencontro entre a precária produção intelectual do seu principal teórico, Otávio Brandão, e a realidade brasileira, como dos demais comunistas que não fizeram esforço algum para compreender um Brasil agrário e que estava em processo de industrialização, por uma stalinização crescente do partido, pela repressão política pelo ecletismo entre Marx, Comte e Spencer, e pelo precário conhecimento das obras de Marx por parte dos comunistas, a conclusão do autor não poderia ser outra. Merece citação:

A dialética, no Brasil, não tinha quem a defendesse. O PCB não via nenhuma utilidade nela e se limitava a permitir que seus militantes brandissem algumas de suas fórmulas, isoladamente, nos embates propagandísticos, como disjecta membra do pensamento de Marx (KONDER, 1988, p. 203).

Em apenas treze páginas no início da sua obra Konder quis esclarecer uma caudalosa literatura sobre a dialética na história da filosofia e resumidamente explicitou o que pensava sobre a mesma, para ele um pensamento de primeira potência, embora muitos autores tenham sublinhado a dialética como autoconsciência ou como reflexividade. Imputar aos criadores o desconhecimento da dialética à la Konder para explicar o papel subalterno na vida política brasileira é desconhecer as dimensões fundamentais da política. A má teoria é apenas um dos aspectos para avaliar a atuação do PC do $B$ no cenário da competição política e pode não ser a fundamental. Caberia então perguntar: teria a oligarquia brasileira, Getúlio Vargas, ou a União Democrática Nacional (UDN), partido criado em 1945, atores decisivos na história política brasileira, compreendido o sentido real do modo de pensar dialético? A resposta de Konder pode parecer sofisticada, mas carece de estudo teórico 
e histórico fundamentados.

\section{REFERÊNCIAS BIBLIOGRÁFICAS}

ARICÓ, José. Marx e a América Latina. Paz e Terra, Rio de Janeiro, RJ, 1982.

BANDEIRA, Moniz; MELO, Clovis; ANDRADE, A. T. $O$ ano vermelho: a revolução russa e seus reflexos no Brasil. Civilização brasileira, Rio de Janeiro, RJ, 1967.

BARRETO, Lima. Bagatelas. São Paulo, Brasiliense, 1956.

BRANDÃO, Gildo Marçal. A esquerda positiva: as duas almas do Partido Comunista, 19201964. Editora Hucitec, São Paulo, SP, 1997.

CARONE, Edgard. Movimento operário no Brasil, 1877-1944. Difel, São Paulo, SP, 1979.

O marxismo no Brasil:(das origens a 1964). Dois Pontos Editora, Rio de Janeiro, RJ, 1986.

(a). O P.C.B - 1922 a 1964.

Difel, São Paulo, SP, 1982.

(b). O P.C.B - 1943 a 1964.

Difel, São Paulo, SP, 1982.

O Tenentismo. Difel, São

Paulo, SP, 1975.

CHILCOTE, Ronald H. Partido Comunista Brasileiro: conflito e integração. Graal, Rio de Janeiro, RJ, 1982.

DULLES, John W.F. Anarquistas e comunistas no Brasil: 1900-1935. Nova Fronteira, Rio de Janeiro, RJ, 1977.

. O comunismo no Brasil,

1935-1945. Nova Fronteira, Rio de Janeiro, RJ, 1985.

JACOBY, Russell. O fim da utopia: política e cultura na era da apatia. Record, Rio de Janeiro, RJ, 2001.
KONDER, Leandro. A democracia e os comunistas no Brasil. Graal, Rio de Janeiro, RJ, 1980.

A derrota da

dialética. Campus, Rio de Janeiro, RJ, 1988.

MAGNANI, Silvia Lang. O movimento anarquista em São Paulo (1906-1917). Editora Brasiliense, São Paulo, SP, 1982.

MORAES FILHO, Evaristo de (ed.). O socialismo brasileiro. Universidade de Brasília, Brasília, DF, 1981.

PANDOLFI, Dulce. Camaradas e Companheiros: história e memória do PCB. Relume Dumará, Rio de Janeiro, RJ, 1995.

PINHEIRO, Paulo Sérgio; HALL, Michael M. A classe operária no Brasil: documentos (18891930) - vol 1: O Movimento Operário. AlfaOmega, São Paulo, SP, 1979.

PEREIRA, Astrojildo. Crítica impura, autores e problemas. Editora Civilização Brasileira, Rio de Janeiro, RJ, 1963.

SEGATTO, José Antônio. Reforma e Rovolução: as vicissitudes políticas do PCB (1954-1964).

Civilização Brasileira, Rio de Janeiro, RJ, 1995.

TAVARES, José Nilo. Marx, o Socialismo e o Brasil. Civilização Brasileira, Rio de Janeiro, RJ, 1983.

VINHAS, Moisés. O Partidão: a luta por um partido de massas, 1922-1974. Hucitec, São Paulo, SP, 1982.

ZAIDAN, Michel. PCB (1922-1929): na busca das origens de um marxismo nacional. Global, São Paulo, SP, 1985. 